\title{
Soluble Dietary Fiber, One of the Most Important Nutrients for the Gut Microbiota
}

\author{
Zhi-Wei Guan ${ }^{1,2,+} \mathbb{B}$, En-Ze Yu ${ }^{1,+}$ and Qiang Feng ${ }^{1,3, *}$ \\ 1 Shandong Provincial Key Laboratory of Oral Tissue Regeneration, Shandong Engineering Laboratory for \\ Dental Materials and Oral Tissue Regeneration, Department of Human Microbiome, School of Stomatology, \\ Shandong University, Jinan 250012, China; guanzhiwei1109@163.com (Z.-W.G.); \\ yuenze31415@163.com (E.-Z.Y.) \\ 2 School of Life Science, Qi Lu Normal University, Jinan 250200, China \\ 3 State Key Laboratory of Microbial Technology, Shandong University, Qingdao 266237, China \\ * Correspondence: fengqiang@sdu.edu.cn \\ + These authors contributed equally to this work.
}

Citation: Guan, Z.-W.; Yu, E.-Z.; Feng, Q. Soluble Dietary Fiber, One of the Most Important Nutrients for the Gut Microbiota. Molecules 2021, 26, 6802. https://doi.org/10.3390/ molecules 26226802

Academic Editor: Smaoui Slim

Received: 17 September 2021

Accepted: 2 November 2021

Published: 11 November 2021

Publisher's Note: MDPI stays neutral with regard to jurisdictional claims in published maps and institutional affiliations.

Copyright: (c) 2021 by the authors. Licensee MDPI, Basel, Switzerland. This article is an open access article distributed under the terms and conditions of the Creative Commons Attribution (CC BY) license (https:/ / creativecommons.org/licenses/by/ $4.0 /)$.

\begin{abstract}
Dietary fiber is a widely recognized nutrient for human health. Previous studies proved that dietary fiber has significant implications for gastrointestinal health by regulating the gut microbiota. Moreover, mechanistic research showed that the physiological functions of different dietary fibers depend to a great extent on their physicochemical characteristics, one of which is solubility. Compared with insoluble dietary fiber, soluble dietary fiber can be easily accessed and metabolized by fiber-degrading microorganisms in the intestine and produce a series of beneficial and functional metabolites. In this review, we outlined the structures, characteristics, and physiological functions of soluble dietary fibers as important nutrients. We particularly focused on the effects of soluble dietary fiber on human health via regulating the gut microbiota and reviewed their effects on dietary and clinical interventions.
\end{abstract}

Keywords: soluble dietary fiber; resistant oligosaccharide; viscous fiber; gut microbiota; human health

\section{Introduction}

The dietary pattern is closely related to human health. Hu et al. identified two major dietary patterns, which are the Prudent and Western diets [1]. The Prudent diet is considered healthy and is characterized by higher intake of vegetables, fruit, legumes, whole grains, fish, and poultry. Compared to the Prudent diet, the Western diet is characterized by abundant red meat, fat, and refined carbohydrates [2,3]. The Western diet contributes to increased risk of non-communicable diseases, especially gastrointestinal diseases and metabolic diseases which are partially attributed to the deficiency of dietary fiber in the Western diet [4-10]. According to the widely accepted definition derived from Codex Alimentarius Alinorm in 2009, dietary fiber is considered as edible carbohydrate polymers with three or more monomeric units that are resistant to endogenous digestive enzymes and thus are neither hydrolyzed nor absorbed in the small intestine [11]. Based on their structures, dietary fibers can be classified into non-starch polysaccharides, resistant starches (RSs), and resistant oligosaccharides. Moreover, the non-carbohydrate polymer, lignin, which coexists with cellulose in plant cell walls, is also considered in this definition as dietary fiber. Based on the source, dietary fibers are mainly comprised three subgroups: (i) Carbohydrate polymers naturally existing in edible plants and consumed as vegetables, fruits, seeds, cereals, and tubers; (ii) edible carbohydrate polymers obtained from raw foods by physical, enzymatic, and chemical means that have a proven physiological benefit (e.g., resistant oligosaccharides, inulin, and psyllium); and (iii) synthetic carbohydrate polymers with a proven physiological benefit (e.g., methylcellulose). [11,12].

Dietary fibers from food pass through the small intestine into the large intestine, where they play physiological roles. Dietary fibers contain a variety of organic polymers, 
with different monomers linked by different glycosidic bonds, showing complex and heterogeneous structure [13]. To help correlate physicochemical characteristics of dietary fiber with their physiological functions, many ways in classifying dietary fiber were established, which include solubility, viscosity, and fermentability [14]. Depending on solubility, dietary fiber can be categorized as insoluble or soluble (SDFs) [15]. The sugar chains in insoluble dietary fiber associate with each other by dense hydrogen bonds, forming a hydrophobic and crystalline structure, which can resist the hydrolysis of exogenous glucosidases. As the most widely distributed and abundant insoluble fiber in nature, cellulose is a polysaccharide with high molecular weight, composed of $\beta$-glucose. It is the main structural component of plant cell walls, which usually combines with hemicellulose, pectin, and lignin [16]. A schematic diagram of molecular structure of cellulose is shown in Figure 1A. Most insoluble dietary fibers, such as cellulose, hemi-cellulose, and lignin, have an effect on bulking fecal material, but are not or just slowly utilized by gut bacteria. On the contrary, SDFs can be readily and quickly metabolized by gut bacteria, in the process of which SDFs significantly influence the abundance and diversity of the human gut microbiota [17]. Studies confirmed that dietary fibers, especially SDFs, can positively regulate the gut microbiota and be metabolized to beneficial products, mainly short-chain fatty acids (SCFAs), thus providing many advantages to human health, such as reducing the risk of gastrointestinal diseases including irritable bowel syndrome (IBS), inflammatory bowel disease (IBD), diverticular disease, functional constipation, fecal incontinence, and colorectal cancer (CRC) [18-20].

A Cellulose, the representative insoluble dietary fiber, which is slowly

A or not fermented in the gut or not

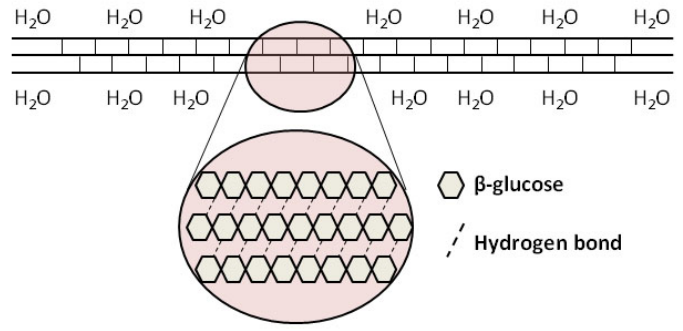

B FOS (left) and GOS (right), two representative resistant oligosaccharides, which are non-viscous and quickly fermented in the gut
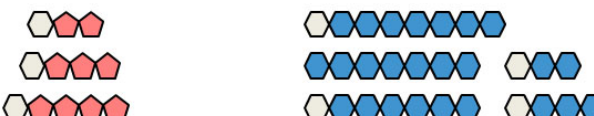

Glucose

$\triangle$ Fructose

Galactose

$\beta$-glucan, the representative viscous soluble dietary fiber,which is

C quickly fermented in the gut

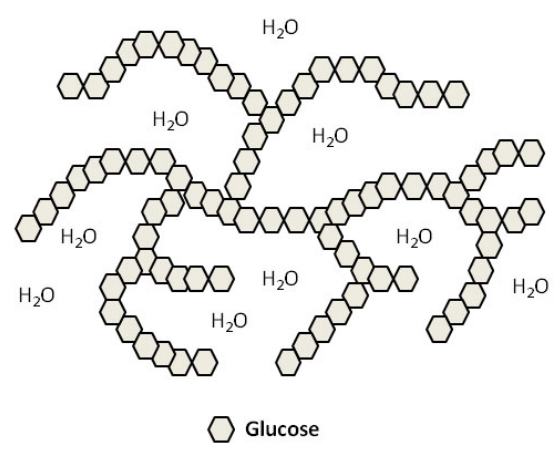

Figure 1. Schematic diagram of the structures of representative insoluble dietary fiber and SDF. (A). The representative insoluble dietary fiber, cellulose. (B). The representative resistant oligosaccharides, FOS and GOS. (C). The representative viscous SDF, $\beta$-glucan. 
Here, we summarized the structures and characteristics of SDFs as well as their effects on the gut microbiota, by which they help to improve human health. We hope that this review can help the readers learn about SDFs and their influence on the gut microbiota, and provide some advice for future research in related fields.

\section{SDFs Include Many Different Substances}

Solubility means the ability of dietary fibers to dissolve in water. Compared to insoluble dietary fibers, SDFs have a high affinity for water. SDFs includes various active substances with different structures, which are mainly composed of resistant oligosaccharides and viscous dietary fibers with a high molecular weight [21]. It is worth noting that solubility can be quite variable depending on not only the structures of fibers but also the external factors such as temperature and $\mathrm{pH}$ value [13]. For example, the solubility of pectin improves with the increase of the abundance of its side chains [22]. In addition, some viscous fibers are obtained via chemically modifying insoluble fibers, such as methylcellulose and type IV RS (RS-4), which were produced from cellulose and type II RS, respectively $[23,24]$. Significantly, SDFs include a large amount of active substances showing the structural complexity, which can be administered in the form of natural foods or dietary supplements [25]. In consideration of the fact that certain dietary fibers, including most SDFs, have the effect of promoting the proliferation of specific probiotics, they are also called microbiota-accessible carbohydrates (MACs) or prebiotics [26]. The definition of prebiotic published in 2017 is a substrate that is selectively utilized by host microorganisms conferring a health benefit [27]. The structures, sources, and physicochemical characteristics of common SDFs are shown in Table 1.

Resistant oligosaccharides, which are also called functional oligosaccharides, refer to oligosaccharides with a degree of polymerization (DP) from 3 to 9 that have prebiotic effects. Fructo-oligosaccharides (FOS) and galacto-oligosaccharides (GOS) are the most studied and typical resistant oligosaccharides. They are easily fermented in the gut because of their low molecular weight and high solubility [28]. A schematic diagram of molecular structures of FOS and GOS is shown in Figure 1B. The preparation of resistant oligosaccharides can be achieved by enzymatic methods, such as hydrolysis and isomerization, and chemical methods $[29,30]$.

Inulin is a chain polysaccharide composed of $D$-fructose linked by a $\beta$-glycosidic bond with a glucose at the end, and with a DP from 2 to 60 [31]. Inulins with a DP less than 10 belong to resistant oligosaccharides, while the others belong to viscous dietary fibers. Due to their large molecular weight and strong hydrophilicity, viscous fibers, including $\beta$-glucan, pectins, and gums, can dissolve in water as well as forming a gelatinous structure at the required critical concentration with a water-holding capacity, which can inhibit the absorption of glucose and lipids in the gut [17]. $\beta$-glucan is composed of D-glucose linked by a $\beta$-glycosidic bond, which is the main structural component of plant cell walls and can also be synthesized by enzyme technology [32]. A schematic diagram of the structure of viscous $\beta$-glucan is shown in Figure 1C. Pectin, a hetero-polysaccharide widely existing in the middle lamella and primary cell walls of the plants, is mainly composed of Dgalacturonic acids linked by an $\alpha-1,4$-glycosidic bond and contains a small amount of rhamnose, arabinose, and galactose [33]. Gums are high-molecular-weight carbohydrates that at low concentrations can combine with water to form gels. There are many types of gums, such as exudate gums (e.g., acacia gum), mucilage gums (e.g., psyllium), and microbial gums (e.g., xanthan gum). Exudate gums are the exudates of certain trees and shrubs, which are wildly applied in the food and other industries because they are easy to produce [34].

Most viscous dietary fibers are rapidly and completely fermented in water with the gelatinous structure disappearing, but there are exceptions, such as psyllium. Psyllium, a widely concerned and studied dietary gum, is a powder ground from the seeds of Plantago ovate. Psyllium is rich in mucilage, which is a mixture of polysaccharides consisting of pentoses, hexoses, and uronic acids [35]. The results of in vitro experiments showed that 
psyllium is a kind of fermentable fiber, but in vivo experiments confirmed that psyllium can hardly be fermented [36]. Therefore, compared with other fermentable viscous fibers, psyllium can always retain its water-holding capacity in the gut, which is the reason why psyllium is used as a laxative in clinics [35].

Methylcellulose is the simplest cellulose derivative. It is made by alkalizing cellulose and then methylating alkaline cellulose by chloromethane, in the process of which methyl groups substitute the hydrogens of the hydroxyls at C-2, C-3, and/or C-6 positions of $\beta$-D-glucose units in cellulose. Finally, the product is purified and ground to a powder. Methylcellulose is approved as a thickener and gelling additive in food processing in many countries [37]. As a viscous dietary fiber, methylcellulose is completely non-fermentable in the gut, but has the function of relaxing the bowel [38].

$\mathrm{RS}$ is a kind of starch, which can escape digestion in the small intestine and then arrives in the colon where it can be utilized by certain specialized bacteria [39]. RS is divided into five subtypes. Although all types of RSs exhibit prebiotic activity, only RS-4 is soluble. RS-4 is a group of starches that are chemically modified by conversion, substitution, or cross-linking in order to lower their digestibility in the small intestine [40].

Table 1. The structures, sources, and physicochemical characteristics of common SDFs and their effects on the gut microbiota.

\begin{tabular}{|c|c|c|c|c|c|}
\hline Type & Structure & Source & Viscosity & Fermentability & Changes Related to the Gut Microbiota \\
\hline FOS & $\begin{array}{l}\text { Sucrose combines with } 1 \\
\text { to } 3 \text { fructoses linked by a } \\
\beta \text {-glycosidic bond }\end{array}$ & $\begin{array}{l}\text { Vegetables, fruits, } \\
\text { produced by } \\
\text { enzyme-catalyzed } \\
\text { synthesis }\end{array}$ & No & Yes & $\begin{array}{l}\text { Increased } \alpha \text {-diversity, } \\
\text { Increased Bifidobacteria and Lactobacilli [41] }\end{array}$ \\
\hline GOS & $\begin{array}{c}\text { Galactose or glucose } \\
\text { combines with } 1 \text { to } 7 \\
\text { galactoses linked by a } \\
\beta \text {-glycosidic bond }\end{array}$ & $\begin{array}{l}\text { Milk, produced by } \\
\text { enzyme-catalyzed } \\
\text { synthesis }\end{array}$ & No & Yes & $\begin{array}{l}\text { Increased } \beta \text {-diversity, Increased } \\
\text { Lactobacillaceae and Lachnospiraceae, } \\
\text { Decreased Ruminococcaceae [42] }\end{array}$ \\
\hline Inulin & $\begin{array}{l}\text { D-fructose linked by a } \\
\beta \text {-glycosidic bond with } \\
\text { glucose at the end }\end{array}$ & Vegetables, fruits, grains & $\begin{array}{l}\mathrm{DP}<9: \text { No } \\
\mathrm{DP} \geq 9: \text { Yes }\end{array}$ & Yes & $\begin{array}{c}\text { Increased } \beta \text {-diversity, Increased } \\
\text { Prevotellaceae [43] } \\
\text { Increased } \alpha \text {-diversity, } \\
\text { Increased Bifidobacteria, } \\
\text { Decreased Desulfovibrio [44] }\end{array}$ \\
\hline$\beta$-glucan & $\begin{array}{l}\text { High polymer composed } \\
\text { of D-glucose linked by a } \\
\beta \text {-glycosidic bond }\end{array}$ & Grains & Yes & Yes & $\begin{array}{l}\text { Increased Bifidobacteria and Lactobacilli, } \\
\text { Decreased Enterobacteriaceae [45] }\end{array}$ \\
\hline Pectins & $\begin{array}{c}\text { Polysaccharides with } \\
\text { complex structures } \\
\text { containing D-galacturonic } \\
\text { acid, rhamnose, arabinose, } \\
\text { and galactose }\end{array}$ & Vegetables, fruits, beans & Yes & Yes & $\begin{array}{c}\text { Increased Bifidobacteria, Lactobacilli, and } \\
\text { Faecalibaculum spp. [46] } \\
\text { Increased } \beta \text {-diversity, Inhibited Citrobacter } \\
\text { rodentium [47] }\end{array}$ \\
\hline Gums & $\begin{array}{l}\text { Polysaccharides with } \\
\text { complex structures } \\
\text { containing mannose, } \\
\text { galactose, glucose, and } \\
\text { D-galacturonic acid }\end{array}$ & $\begin{array}{l}\text { Leguminous plants, } \\
\text { nuts, seaweeds }\end{array}$ & Yes & Yes & $\begin{array}{l}\text { Increased Bifidobacteria and Lactobacilli [48] } \\
\text { Inhibited Clostridium histolyticum [49] }\end{array}$ \\
\hline Psyllium & $\begin{array}{c}\text { Mixture of } \\
\text { polysaccharides consisting } \\
\text { of arabinose, xylose, } \\
\text { galactose, rhamnose, and } \\
\text { D-galacturonic acid }\end{array}$ & Plantago ovate & Yes & No & No \\
\hline Methylcellulose & $\begin{array}{l}\text { Long-chain substituted } \\
\text { cellulose, in which about } \\
30 \% \text { of the hydroxyl } \\
\text { groups exist in the form of } \\
\text { methoxyl }\end{array}$ & Synthesized & Yes & No & No \\
\hline RS-4 & $\begin{array}{l}\text { Chemically modified } \\
\text { starch, such as acetyl } \\
\text { starch, hydroxypropyl } \\
\text { starch, heat-modified } \\
\text { starch, and } \\
\text { phosphorylated starch }\end{array}$ & Synthesized & Yes & Yes & $\begin{array}{c}\text { Increased Bacteroides, Bifidobacteria, } \\
\text { Lactobacilli, Coprococcus, and Allobaculum } \\
{[50-52]}\end{array}$ \\
\hline
\end{tabular}

FOS: fructo-oligosaccharides, GOS: galacto-oligosaccharides, DP: degree of polymerization, RS-4: type IV resistant starch. 


\section{Mechanism in the Utilization of SDFs by the Gut Microbiota}

The human body is occupied by trillions of microorganisms, most of which are bacteria [53]. They are closely related to human health and the gut is their most densely populated habitat [54]. In 2020, Almeida et al. established the Unified Human Gastrointestinal Genome (UHGG) collection by editing and analyzing previous human gut microbiome datasets. UHGG consists of 204,938 non-redundant genomes from 4644 gut prokaryotes and is the most comprehensive sequence database of the human gut microbiome so far [55]. Firmicutes and Bacteroidetes are the dominant phyla in the gut microbiota [56]. The digestive enzymes of the human body cannot degrade SDFs. When SDFs in foods enter the colon though the small intestine, the gut bacteria can degrade SDFs into oligosaccharides or monosaccharides through different degradation systems, and then absorb them by specific transport systems for energy source [57]. Although each organism contains relatively few cellulolytic enzymes, the intestinal microbes in total contain about 130 glycoside hydrolase (GH) families, 22 polysaccharides lyase (PL) families, and 16 carbohydrate esterase families, which provide the microbiota with the flexibility to switch between different fiber energy sources [58].

In terms of the degradation of long-chain dietary fibers, in vitro studies by co-culturing with human fecal samples indicated that the species from the phylum Firmicutes (e.g., Ruminococcus bromii, Eubacterium rectale, Clostridium spp., and Roseburia spp.), Bifidobacterium spp., and Bacteroides spp., are the major degraders of RSs $[59,60]$. However, bioinformatic analysis of a model human microbiome constructed from 177 human microbial genomes revealed that the bacteria from the phylum Bacteroidetes are the likely primary degraders of the various complex polysaccharides in the plant cell walls [61]. Many gut microbes evolved diverse strategies to utilize SDFs. For example, Bacteroides, the typical Gram-negative bacteria, is the most widely studied microbe in the field of polysaccharide transport and utilization of the gut microbiota due to its efficient polysaccharide degradation system, which may be the reason that Bacteroides is the dominant bacteria in the gut microbiota. About $20 \%$ of the genes in the genome of Bacteroides are involved in the utilization of polysaccharides [57]. Its transportation and decomposition of polysaccharides require the participation of multiple functional proteins and the system containing these proteins is called the starch utilization system (Sus). Sus consists of eight components, SusA-SusG and SusR, which are responsible for the detection, binding, hydrolysis, and transport of exogenous polysaccharides, respectively [62]. Notably, all Bacteroides possess the orthologous components of the Sus system, many of which have been demonstrated to be responsible for the absorption and utilization of specific SDFs such as inulin and pectin [63]. Moreover, certain Gram-positive bacteria in the gut microbiota are also prominent in the process of glycan utilization. The most representative Gram-positive intestinal saccharolytic microbe is the Bifidobacterium genus from the Actinobacteria phylum [64]. Bioinformatics analyses showed that the genes encoding modules involved in carbohydrate utilization account for nearly $13 \%$ of the identified genes in the bifidobacterial genome [65]. Unlike Gram-negative bacteria, Gram-positive Bifidobacteria have no periplasmic space. Therefore, complex polysaccharides first need to be digested into oligosaccharides extracellularly by the GHs anchored on the cell surface. Then, the produced oligosaccharides are transported into the cytoplasm for further degradation or shared by other members in the gut microbiota as nutritional sources [66]. The bacterial ability to degrade fibers is relative to the chain length of fibers. Resistant oligosaccharides are usually easier to degrade than polysaccharides. Many bacteria in the gut microbiota can utilize short-chain fibers. Besides the degraders of long-chain fibers, Faecalibacterium prausnitzii and Lactobacillus spp. were found to be able to utilize FOS in vitro [67]. Except for the decomposition of SDFs, the subsequent production of SCFAs is also necessary for human health. SCFAs are the fatty acids with 1 to 6 carbon atoms, mainly including acetate, propionate, and butyrate. Succinate and lactate are also produced by intestinal microbes, but they are usually regarded as intermediates due to their small amounts and the conversion of them to SCFAs by other microorganisms. The current findings have demonstrated that the health 
benefits of SDFs depend more on SCFAs [15,20]. Many intestinal bacteria have been proved to be specific SCFA producers, although some of them have a poor ability to degrade SDFs (e.g., Anaerostipes spp., Coprococcus spp., Dialister spp., Veillonella spp., and Salmonella spp.) $[20,68]$. The process of degrading and metabolizing SDFs by the gut microbiota is illustrated as Figure 2.

$$
\text { Long-chain SDFs }
$$

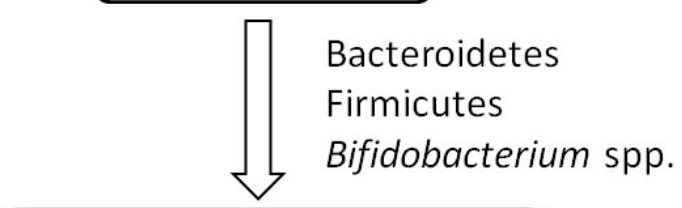

$$
\begin{gathered}
\text { Short-chain SDFs and } \\
\text { Resistant oligosaccharides }
\end{gathered}
$$

Bacteroidetes

Firmicutes

Bifidobacterium spp.

Faecalibacterium prausnitzii

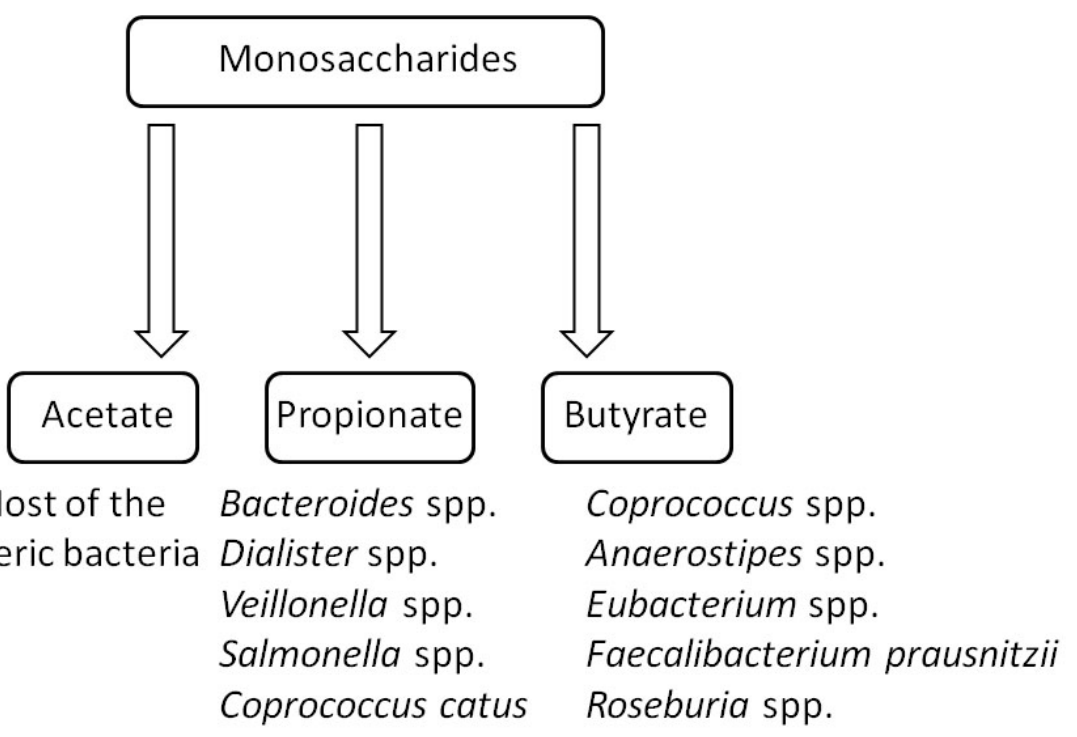

Figure 2. Schematic diagram of the process of degrading and metabolizing SDFs by the gut microbiota.

The above data are indicative of the link between the ability of the intestinal bacteria in glycan utilization and its corresponding ecological niche in the human gut. It also makes SDF metabolism closely related to human health.

\section{Effects of SDFs on the Gut Microbiota}

Dietary fibers, especially SDFs, provide the main carbon and energy source for the gut microbiota. SDFs have prebiotic effects by increasing the beneficial bacteria and improving the intestinal environment [69].

For example, FOS can effectively increase the bacterial diversity of the human gut microbiota and improve the abundance of Bifidobacteria and Lactobacilli [41]. The results of the study by Yang et al. showed that the administration of GOS is conductive to improving neuro-inflammatory and cognitive dysfunction in a rat model of abdominal surgery. Furthermore, in-depth fecal microbiota analysis by $16 \mathrm{~S}$ rRNA sequencing revealed that the administration of GOS can induce a significant increase in $\beta$-diversity of the gut microbiota 
and the proliferation of Bifidobacterium and other potentially anti-inflammatory bacteria [42]. Inulin was confirmed to be beneficial to health by regulating the gut microbiota. In $o b / o b$ mice, it was found that an inulin-containing diet can improve fat accumulation and glucose intolerance. Further fecal microbiota analysis displayed that the $\beta$-diversity of the $o b / o b$ mice tended to the level of the wild type mice and the Prevotellaceae UCG 001 family was significantly enriched, which positively affected the leptin-related pathways in the $o b / o b$ mice [43]. In a randomized controlled trial on healthy adults, the addition of agave inulin bettered the diversity and activity of the gut microbiota including increasing Bifidobacteria and depleting Desulfovibrio [44]. Cereal is the main dietary source of $\beta$-glucan. A study in rats showed that the administration of cereal $\beta$-glucan can promote the growth of Bifidobacteria and Lactobacilli, whereas it can reduce the abundance of Enterobacteriaceae in a dose-dependent manner [45]. Pectin rich in rhamnogalacturonan-I which is refined from citrus segment membranes was demonstrated to significantly promote the production Bifidobacteria, Lactobacilli, and Faecalibaculum spp. in C57BL/6J male mice, and to be metabolized to SCFAs, which reduces the $\mathrm{pH}$ value in the intestine [46]. Another experiment with C57BL/6J female mice showed that administration of pectin extracted from orange peel relieved the development of Citrobacter rodentium-induced colitis, which may be because of the increase in the diversity of the gut microbiota [47]. Acacia gum, also known as gum Arabic, a branched-chain polysaccharide exudate gum mainly produced from Acacia senegal, is composed of arabinose and galactose [34]. Calame et al. found that the intake of acacia gum at $10 \mathrm{~g} / \mathrm{d}$ was effective in increasing the abundance of Bifidobacteria and Lactobacilli in healthy human volunteers [48]. The results of an in vitro study by Rawi et al. showed that acacia gum significantly increased the abundance of Bifidobacteria while it inhibited that of Clostridium histolyticum, the bacterium which gives rise to gut dysbiosis. Moreover, acacia gum promoted the production of butyrate, which may also contribute to ameliorating the gut microbiota [49]. RSs, both insoluble and soluble, can be fermented and utilized by colonic microorganisms. They can increase the abundance of Bacteroides, Bifidobacteria, Lactobacilli, Coprococcus, and Allobaculum [50-52] and cooperatively perform their prebiotic effects with other active constituents such as chitosan oligosaccharide [70]. The effects of SDFs on the gut microbiota are summarized in Table 1.

Except for the different types and amounts of SDFs and other polysaccharides from food, dietary and endogenous proteins and mucins that come from intestinal epithelial cells are also nutrients for the gut microbiota [66,71]. The intestinal epithelium is covered and protected by a mucous layer to keep bacteria isolated from the mucosa [72]. SDFs and SCFAs stimulate mucus production and secretion [73]. Inadequate intake of SDFs will reduce the number of probiotics and transfer the metabolism of the gut microbiota to utilize amino acids in the other substrates, which can give rise to injury of the intestinal mucosa by accumulation of harmful metabolites, such as branched-chain fatty acids, ammonia, amines, $\mathrm{N}$-nitroso compounds, and phenolic compounds [74]. Therefore, a dietary pattern with high sugar, fat, and protein but low fiber may result in the development of chronic inflammatory diseases such as IBD, CRC, allergies, cardiovascular disease, and obesity [75-77]. Sufficient intake of SDFs can protect the intestinal mucosa from degradation by intestinal bacteria and to a certain extent prevent these diseases.

Studying the impact of SDFs on health via the gut microbiota is sophisticated due to certain interferences. First, animal experiments often administer refined or modified SDFs in the form of feed additives. However, the physicochemical properties of SDFs such as viscosity or fermentability may be different when SDFs are eaten in the form of natural foods, thus altering their physiological functions. Second, natural foods rich in SDFs also contain other beneficial nutrients, such as minerals and phytochemicals, which make it difficult to determine the precise effects of SDFs alone on human health. Therefore, whether the results from animal experiments can be applied to humans requires further study. 


\section{SDFs and Their Metabolites Display Important Physiological Effects on Human Health}

Although SDFs hardly directly provide energy for humans, SDFs per se exhibits specific physiological functions as recognized nutrients. In addition to stimulating the production and secretion of mucus, SDFs and SCFAs have other important physiological functions. In this section, we summarized the physiological functions of SDFs, including those that are attributed to SCFAs.

\subsection{Increase Satiety and Reduce Energy Intake}

Viscous SDFs retard the hydrolysis and absorption of energetic nutrients from food in the small intestine, such as starch and triglyceride. So, SDFs can significantly reduce the total intake of energy as well as glucose and cholesterol, so they contribute to slowing down the process of obesity, type 2 diabetes mellitus (T2DM), hyperlipidemia, and related metabolic diseases $[78,79]$. Then, the chyme gets to and stimulates the terminal ileum, where the mucosa responses and releases glucagon-like peptide-1 (GLP-1). The results from the experiments in human and pigs indicated that GLP-1 can inhibit gastric emptying and reduce intestinal peristalsis $[80,81]$. Therefore, viscous SDFs are helpful to control appetite, improve insulin sensitivity, and reduce weight.

\subsection{Promote the Metabolism and Absorption of Active Substances}

Many viscous SDFs can provide a platform for the metabolism of active substances. Take the bile acids as an example. Bile acids are produced in the liver and metabolized by enzymes from intestinal bacteria, which not only promote the absorption of dietary fat but also play indispensable roles in maintaining the healthy gut microbiota, balanced lipid and carbohydrate metabolism, insulin sensitivity, and innate immunity [82]. In the upper segment of the ileum and colon, conjugated primary bile acids combine with SDFs, where they are hydrolyzed to free primary bile acids by the bile salt hydrolase (BSH) from the intestinal bacteria, mainly Bacteroides and Lactobacilli [83]. Then, $7 \alpha$-dehydroxylase also from the intestinal bacteria, such as Clostridium spp. and Eubacterium spp., catalyzes the free primary bile acids to secondary bile acids $[84,85]$.

In addition to organic substrates, viscous SDFs can bind with inorganic nutrients such as metal ions. It was reported that after being bound with SDFs, calcium, magnesium, iron, copper, and zinc are transported to the distal colon. With the degradation of SDFs by the local bacteria, the ions are released and exhibit specific effects including resisting pathogens, increasing the diversity of the intestinal bacterial community, and protecting the gut from infection [76]. Furthermore, SCFAs produced via the gut microbiota fermenting SDFs combine with ions to form soluble salts, which are more prone to absorption by the colon $[86,87]$.

\subsection{SCFAs Act as Histone Deacetylase (HDAC) Inhibitors}

Intracellular butyrate and propionate inhibit the activity of HDACs in colon cells and immune cells, leading to histone hyperacetylation, which in turn affects gene expression and cell differentiation, proliferation, and apoptosis [88]. Many studies have shown that SCFAs have important anti-inflammatory effects due to HDAC inhibition. For example, SCFAs can down-regulate proinflammatory cytokines such as interleukin-6 (IL-6) and IL-12 in colonic macrophages and differentiate dendritic cells from bone marrow stem cells [89,90]. Moreover, SCFAs can induce colonic regulatory T cells (Tregs) in mice [91]. There is also evidence that butyrate and propionate can induce the differentiation of Tregs, which can express the transcription factor Foxp3 via increasing the acetylation at the gene locus of foxP3. Foxp3 is found to play a crucial role in controlling intestinal inflammation in mice [92]. In addition, butyrate and propionate activate the AP-1 signaling pathway in human epithelial cells, which plays an important role in controlling proliferation and inducing apoptosis of colon cancer cells [93]. 
In brief, SCFAs, especially butyrate, not only provide the most energy for colon cells, but also aid to a large extent in the prevention of inflammation and CRC due to HDAC inhibition.

\subsection{SCFAs Are Important Ligands for Specific G-Protein Coupled Receptors (GPCRs)}

In addition to acting as HDAC inhibitors, SCFAs also exert important physiological functions as ligands for GPCRs. Three GPCRs (GPR41, GPR43, and GPR109A) involved in immune regulation were proven to specifically respond to free fatty acids. Therefore, GPR43 and GPR41 were also named FFAR (free fatty acid receptor) 2 and FFAR3, respectively [94].

In mice, butyrate can increase the secretion of Tregs, IL-18, and T cells producing IL-10 in intestinal epithelial cells via stimulating GPR109A [95]. Additionally, the study by Macia et al. in mice indicated that SCFAs derived from a high-fiber diet stimulated GPR43 and GPR109A to activate the NLRP3 inflammasome, which produces IL-18. This effect maintains intestinal homeostasis by decreasing the inflammatory response of the gut and maintaining the integrity of the mucosal barrier, which prevents bacterial invasion and infection [96]. In the intestine and white adipose tissue (WAT) of mice, SCFA-dependent GPR43 stimulation (especially acetate and propionate) displays beneficial effects in ameliorating the metabolism of glucose and lipids by GLP-1 secretion and anti-lipolytic activity, respectively [97]. GPR41 also plays a role in the regulating appetite. Samuel et al. reported that by binding with GPR41, SCFAs induce the production of peptide YY, which inhibits gastrointestinal motility and gastric acid secretion in mice [98].

The above studies indicated that SCFAs have significant immunologic and metabolic functions as ligands for GPCRs, affecting the incidence of IBD, CRC, and other cancers as well as chronic metabolic diseases.

The identified physiological effects of SDFs and SCFAs on human health are summarized in Figure 3.

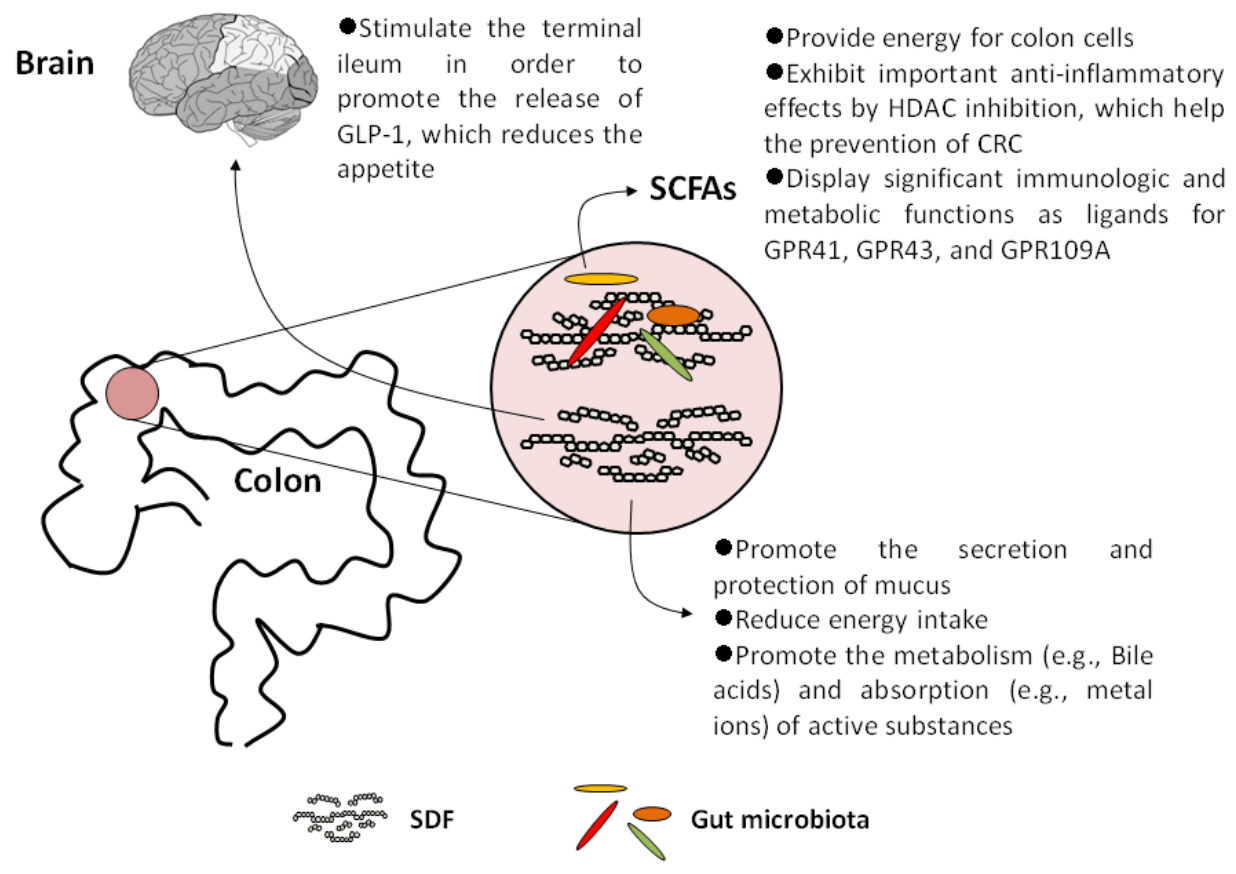

Figure 3. Summary of identified physiological effects of SDF and SCFAs on human health.

\section{Safety of SDFs}

Although SDFs show excellent health effects, it cannot be ignored that inappropriate SDF intake may lead to certain health hazards, which depend on the type and quantity of SDFs as well as the physiological background of the host.

First, a sudden increase of SDF intake, even when consumed judiciously, may lead to abdominal distension, flatulence, constipation, diarrhea, and other syndromes of IBS $[99,100]$. 
Second, as mentioned above, the binding by SDFs can promote to a certain extent the absorption of certain micronutrients such as some metal ions in the colon. However, the study on six healthy young women by Riedl et al. indicated that the bioavailability of $\beta$-carotene, lycopene, and lutein, was markedly reduced by three different kinds of SDFs, pectin, guar gum, and alginate [101]. This suggests that excessive SDF intake may be disadvantageous to certain people with micronutrient deficiencies. In addition, Bruggencate et al. reported that the rapid fermentation of FOS by endogenous microbiota damaged the intestinal mucosal barrier and increased intestinal permeability, which caused pathogen infection in rats [102]. Moreover, the study by Singh et al. found that formulating a diet rich in refined inulin or other SDFs to feed TLR5-deficient (T5KO) mice with obesity caused by dysregulated gut microbiota, about $40 \%$ of mice had a lower weight than before. However, many mice suffered from icteric hepatocellular carcinoma (HCC). Further research revealed that SDF-induced HCC in mice developed via elevation of secondary bile acids in the systemic circulation, cholestasis, and hepatocyte death, followed by neutrophilic inflammation of the liver. Furthermore, fecal microbiota analysis by $16 \mathrm{~S}$ rRNA sequencing showed that the HCC-prone mice exhibited gut dysbiosis characterized by a loss in species richness and diversity and an increase in the Proteobacteria phylum and the fiber-utilizing microbes including Clostridium spp. However, such HCC in T5KO mice cannot be induced by cellulose, the insoluble and non-fermentable fiber, and it was not observed in germ-free nor antibiotics-treated mice [103]. Although acting as a kind of metabolite with important physiological functions, certain bile acids, especially secondary bile acids, were proven to be cytotoxic and cancer-promoting, which have adverse effects on the structure and function of the colonic epithelium by many mechanisms including DNA oxidative damage, inflammation, NF- $\mathrm{KB}$ activation, reducing apoptosis, and differentiation, as well as enhancing cell proliferation [104]. Apart from HCC, the changed bile acid profile derived from dysregulated gut microbiota was demonstrated to be associated with a variety of digestive diseases. For example, many patients suffering from CRC exhibited abnormal bile acid metabolism characteristic of redundant secondary bile acids. These redundant secondary bile acids, including deoxycholic acid, lithocholic acid, and taurochenodeoxycholic acid, originate in the aberrant elevation of certain gut bacteria expressing BSH and $7 \alpha$-dehydroxylase, whose proportion is significantly higher than that in the gut microbiota of healthy people [82]. These facts hinted that, despite notable physiological benefits, fortification of diets with SDFs should be done with great caution as it may cause severe digestive disorders, especially under the background of dysregulated gut microbiota.

\section{Conclusions and Prospects}

Studies have confirmed that the gut microbiota is closely related to human health. The results from experiments with mice showed that the genetic background contributed to less than $12 \%$ of the difference of the gut microbiota, but dietary structure and habits contributed to $57 \%$ [105]. SDFs have a significant advantage in improving the gut microbiota due to their high fermentation efficiency. Furthermore, many prospective cohort studies showed that the diversity of the gut microbiota is negatively correlated with the incidence rate of many chronic diseases, including IBD, CRC, obesity, and T2DM [106-110]. In view of the fact that specific SDFs can promote the proliferation of specific intestinal bacteria, a diet rich in various SDFs is beneficial to health. A reasonable combination of various SDFs by raw food is undoubtedly helpful to improve the gut microbiota. In addition, studies also showed that the host response to SDF intervention is personalized, and the results to a significant extent depend on the individual's intestinal ecology before treatment [15]. Therefore, based on the precise analysis of host gut ecology, the personalized treatment of dietary intervention with SDFs combined with antibiotic therapy and/or fecal microbial transplantation (FMT), may be effective in improving health, especially in the prevention and treatment of intestinal diseases. SDFs have a promising future by increasing the community of beneficial microorganisms and their products of growth and metabolism in 
the host. Notably, certain prospective cohort studies showed that insoluble fibers in diet is more protective against some metabolic diseases (e.g., T2DM) than SDFs [111]. At the same time, considering the side effects of SDFs via dysregulated microbial fermentation, precise SDF intake as well as a reasonable association with insoluble dietary fiber on the basis of the background of the gut microbiota in hosts is of great importance in achieving the goal of disease prevention and cure. With the development of microbiome analysis, the functions of intestine ecology will be clearer. The precise understanding of metabolic pathways and end products involved with the utilization of SDFs and other nutrients by the gut microbiota is the hotspot of the present research. There is an urgent need to elucidate the interactions between bacterial strain levels and specific types of SDFs, which may undoubtedly help improve human health by accurately determining the diversity and functions of the gut microbiota.

Author Contributions: Conceptualization, Q.F.; writing, Z.-W.G. and E.-Z.Y.; Figures and table made by Z.-W.G.; supervision, Q.F. All authors have read and agreed to the published version of the manuscript.

Funding: We gratefully acknowledge the financial support from The National Natural Science Foundation of China (Grant No. 81630072, 82071122), Program of Taishan Young from Shandong Province, Oral Microbiome Innovation Team of Young Scientist Project of Shandong Province (Grant No. 2020KJK001), The National High-level Young Scientist Project Foundation (2019), Excellent Young Scientist Foundation of Shandong Province (Grant No. ZR202102230369), and Higher Educational Science and Technology Program of Shandong Province (Grant No. J1LLE53). The funders had no role in the study design, data collection and analysis, decision to publish, or preparation of the manuscript.

Institutional Review Board Statement: Not applicable.

Informed Consent Statement: Not applicable.

Data Availability Statement: Not applicable.

Acknowledgments: Thanks to Edward C. Mignot, Shandong University, for linguistic advice.

Conflicts of Interest: The authors declare no conflict of interest.

\section{References}

1. Hu, F.B.; Rimm, E.B.; Stampfer, M.J.; Ascherio, A.; Spiegelman, D.; Willett, W.C. Prospective study of major dietary patterns and risk of coronary heart disease in men. Am. J. Clin. Nutr. 2000, 72, 912-921. [CrossRef] [PubMed]

2. van Dam, R.M.; Rimm, E.B.; Willett, W.C.; Stampfer, M.J; Hu, F.B. Dietary patterns and risk for type 2 diabetes mellitus in U.S. men. Ann. Intern. Med. 2002, 136, 201-209. [CrossRef] [PubMed]

3. Strate, L.L.; Keeley, B.R.; Cao, Y.; Wu, K.; Giovannucci, E.L.; Chan, A.T. Western Dietary Pattern Increases, and Prudent Dietary Pattern Decreases, Risk of Incident Diverticulitis in a Prospective Cohort Study. Gastroenterology 2017, 152, 1023-1030.e2. [CrossRef] [PubMed]

4. Christ, A.; Lauterbach, M.; Latz, E. Western Diet and the Immune System: An Inflammatory Connection. Immunity 2019, 51, 794-811. [CrossRef]

5. Sdona, E.; Georgakou, A.V.; Ekström, S.; Bergström, A. Dietary Fibre Intake in Relation to Asthma, Rhinitis and Lung Function Impairment-A Systematic Review of Observational Studies. Nutrients 2021, 13, 3594. [CrossRef]

6. Larrosa, S.; Luque, V.; Grote, V.; Closa-Monasterolo, R.; Ferré, N.; Koletzko, B.; Verduci, E.; Gruszfeld, D.; Xhonneux, A.; Escribano, J. Fibre Intake Is Associated with Cardiovascular Health in European Children. Nutrients 2020, 13, 12. [CrossRef]

7. O'Keefe, S.J. Diet, microorganisms and their metabolites, and colon cancer. Nat. Rev. Gastroenterol. Hepatol. 2016, 13, 691-706. [CrossRef]

8. Zhao, L.; Zhang, F.; Ding, X.; Wu, G.; Lam, Y.Y.; Wang, X.; Fu, H.; Xue, X.; Lu, C.; Ma, J.; et al. Gut bacteria selectively promoted by dietary fibers alleviate type 2 diabetes. Science 2018, 359, 1151-1156. [CrossRef]

9. Canfora, E.E.; Meex, R.C.R.; Venema, K.; Blaak, E.E. Gut microbial metabolites in obesity, NAFLD and T2DM. Nat. Rev. Endocrinol. 2019, 15, 261-273. [CrossRef] [PubMed]

10. Dinan, T.G.; Cryan, J.F. The Microbiome-Gut-Brain Axis in Health and Disease. Gastroenterol. Clin. N. Am. 2017, 46, 77-89. [CrossRef]

11. Stephen, A.M.; Champ, M.M.; Cloran, S.J.; Fleith, M.; van Lieshout, L.; Mejborn, H.; Burley, V.J. Dietary fibre in Europe: Current state of knowledge on definitions, sources, recommendations, intakes and relationships to health. Nutr. Res. Rev. 2017, 30, 149-190. [CrossRef] 
12. Davani-Davari, D.; Negahdaripour, M.; Karimzadeh, I.; Seifan, M.; Mohkam, M.; Masoumi, S.J.; Berenjian, A.; Ghasemi, Y. Prebiotics: Definition, Types, Sources, Mechanisms, and Clinical Applications. Foods 2019, 8, 92. [CrossRef] [PubMed]

13. Lovegrove, A.; Edwards, C.H.; De Noni, I.; Patel, H.; El, S.N.; Grassby, T.; Zielke, C.; Ulmius, M.; Nilsson, L.; Butterworth, P.J.; et al. Role of polysaccharides in food, digestion, and health. Crit. Rev. Food Sci. Nutr. 2017, 57, 237-253. [CrossRef] [PubMed]

14. Williams, B.A.; Mikkelsen, D.; Flanagan, B.M.; Gidley, M.J. “Dietary fibre": Moving beyond the "soluble/insoluble" classification for monogastric nutrition, with an emphasis on humans and pigs. J. Anim. Sci. Biotechnol. 2019, 10, 45. [CrossRef]

15. O'Grady, J.; O'Connor, E.M.; Shanahan, F. Review article: Dietary fibre in the era of microbiome science. Aliment. Pharmacol. Ther. 2019, 49, 506-515. [CrossRef] [PubMed]

16. Takahashi, T.; Karita, S.; Ogawa, N.; Goto, M. Crystalline cellulose reduces plasma glucose concentrations and stimulates water absorption by increasing the digesta viscosity in rats. J. Nutr. 2005, 135, 2405-2410. [CrossRef]

17. McRorie, J.W., Jr.; McKeown, N.M. Understanding the Physics of Functional Fibers in the Gastrointestinal Tract: An EvidenceBased Approach to Resolving Enduring Misconceptions about Insoluble and Soluble Fiber. J. Acad. Nutr. Diet. 2017, 117, $251-264$. [CrossRef]

18. Gill, S.K.; Rossi, M.; Bajka, B.; Whelan, K. Dietary fibre in gastrointestinal health and disease. Nat. Rev. Gastroenterol. Hepatol. 2021, 18, 101-116. [CrossRef]

19. Staller, K.; Song, M.; Grodstein, F.; Whitehead, W.E.; Matthews, C.A.; Kuo, B.; Chan, A.T. Increased Long-Term Dietary Fiber Intake Is Associated with a Decreased Risk of Fecal Incontinence in Older Women. Gastroenterology 2018, 155, 661-667.e1. [CrossRef] [PubMed]

20. Koh, A.; De Vadder, F.; Kovatcheva-Datchary, P.; Bäckhed, F. From Dietary Fiber to Host Physiology: Short-Chain Fatty Acids as Key Bacterial Metabolites. Cell 2016, 165, 1332-1345. [CrossRef]

21. Chawla, R.; Patil, G. Soluble dietary fiber. Compr. Rev. Food Sci. Food Saf. 2010, 9, 178-196. [CrossRef]

22. Ralet, M.C.; Dronnet, V.; Buchholt, H.C.; Thibault, J.F. Enzymatically and chemically de-esterified lime pectins: Characterisation, polyelectrolyte behaviour and calcium binding properties. Carbohydr. Res. 2001, 336, 117-125. [CrossRef]

23. Nasatto, P.L.; Pignon, F.; Silveira, J.L.M.; Duarte, M.E.R.; Noseda, M.D.; Rinaudo, M. Methylcellulose, a Cellulose Derivative with Original Physical Properties and Extended Applications. Polymers 2015, 7, 777-803. [CrossRef]

24. Birt, D.F.; Boylston, T.; Hendrich, S.; Jane, J.L.; Hollis, J.; Li, L.; McClelland, J.; Moore, S.; Phillips, G.J.; Rowling, M.; et al. Resistant starch: Promise for improving human health. Adv. Nutr. 2013, 4, 587-601. [CrossRef]

25. Hamaker, B.R.; Tuncil, Y.E. A perspective on the complexity of dietary fiber structures and their potential effect on the gut microbiota. J. Mol. Biol. 2014, 426, 3838-3850. [CrossRef] [PubMed]

26. Payling, L.; Fraser, K.; Loveday, S.M.; Sims, I.; Roy, N.; McNabb, W. The effects of carbohydrate structure on the composition and functionality of the human gut microbiota. Trends Food Sci. Technol. 2020, 97, 233-248. [CrossRef]

27. Gibson, G.R.; Hutkins, R.; Sanders, M.E.; Prescott, S.L.; Reimer, R.A.; Salminen, S.J.; Scott, K.; Stanton, C.; Swanson, K.S.; Cani, P.D.; et al. Expert consensus document: The International Scientific Association for Probiotics and Prebiotics (ISAPP) consensus statement on the definition and scope of prebiotics. Nat. Rev. Gastroenterol. Hepatol. 2017, 14, 491-502. [CrossRef]

28. Sanders, M.E.; Merenstein, D.J.; Reid, G.; Gibson, G.R.; Rastall, R.A. Probiotics and prebiotics in intestinal health and disease: From biology to the clinic. Nat. Rev. Gastroenterol. Hepatol. 2019, 16, 605-616. [CrossRef] [PubMed]

29. Wilson, B.; Whelan, K. Prebiotic inulin-type fructans and galacto-oligosaccharides: Definition, specificity, function, and application in gastrointestinal disorders. J. Gastroenterol. Hepatol. 2017, 32 (Suppl. 1), 64-68. [CrossRef]

30. Wu, J.; Yang, R.; Gao, M.; Zhang, H.; Zhan, X. Synthesis of functional oligosaccharides and their derivatives through cocultivation and cellular NTP regeneration. Adv. Appl. Microbiol. 2021, 115, 35-63. [CrossRef]

31. Man, S.; Liu, T.; Yao, Y.; Lu, Y.; Ma, L.; Lu, F. Friend or foe? The roles of inulin-type fructans. Carbohydr. Polym. 2021, $252,117155$. [CrossRef]

32. Bulmer, G.S.; de Andrade, P.; Field, R.A.; van Munster, J.M. Recent advances in enzymatic synthesis of $\beta$-glucan and cellulose. Carbohydr. Res. 2021, 508, 108411. [CrossRef] [PubMed]

33. Schmitz, K.; Protzko, R.; Zhang, L.; Benz, J.P. Spotlight on fungal pectin utilization-From phytopathogenicity to molecular recognition and industrial applications. Appl. Microbiol. Biotechnol. 2019, 103, 2507-2524. [CrossRef]

34. Barak, S.; Mudgil, D.; Taneja, S. Exudate gums: Chemistry, properties and food applications-A review. J. Sci. Food Agric. 2020, 100, 2828-2835. [CrossRef] [PubMed]

35. McRorie, J.W.; Daggy, B.P.; Morel, J.G.; Diersing, P.S.; Miner, P.B.; Robinson, M. Psyllium is superior to docusate sodium for treatment of chronic constipation. Aliment. Pharmacol. Ther. 1998, 12, 491-497. [CrossRef]

36. McRorie, J. Clinical data support that psyllium is not fermented in the gut. Am. J. Gastroenterol. 2013, 108, 1541. [CrossRef]

37. Souza, P.R.; de Oliveira, A.C.; Vilsinski, B.H.; Kipper, M.J.; Martins, A.F. Polysaccharide-Based Materials Created by Physical Processes: From Preparation to Biomedical Applications. Pharmaceutics 2021, 13, 621. [CrossRef]

38. Topping, D.L.; Oakenfull, D.; Trimble, R.P.; Illman, R.J. A viscous fibre (methylcellulose) lowers blood glucose and plasma triacylglycerols and increases liver glycogen independently of volatile fatty acid production in the rat. Br. J. Nutr. 1988, 59, 21-30. [CrossRef] [PubMed]

39. Bello-Perez, L.A.; Flores-Silva, P.C.; Agama-Acevedo, E.; Tovar, J. Starch digestibility: Past, present, and future. J. Sci. Food Agric. 2020, 100, 5009-5016. [CrossRef] 
40. DeMartino, P.; Cockburn, D.W. Resistant starch: Impact on the gut microbiome and health. Curr. Opin. Biotechnol. $2020,61,66-71$. [CrossRef]

41. Tandon, D.; Haque, M.M.; Gote, M.; Jain, M.; Bhaduri, A.; Dubey, A.K.; Mande, S.S. A prospective randomized, double-blind, placebo-controlled, dose-response relationship study to investigate efficacy of fructo-oligosaccharides (FOS) on human gut microflora. Sci. Rep. 2019, 9, 5473. [CrossRef] [PubMed]

42. Yang, X.D.; Wang, L.K.; Wu, H.Y.; Jiao, L. Effects of prebiotic galacto-oligosaccharide on postoperative cognitive dysfunction and neuroinflammation through targeting of the gut-brain axis. BMC Anesthesiol. 2018, 18, 177. [CrossRef]

43. Song, X.; Zhong, L.; Lyu, N.; Liu, F.; Li, B.; Hao, Y.; Xue, Y.; Li, J.; Feng, Y.; Ma, Y.; et al. Inulin Can Alleviate Metabolism Disorders in ob/ob Mice by Partially Restoring Leptin-related Pathways Mediated by Gut Microbiota. Genom. Proteom. Bioinform. 2019, 17, 64-75. [CrossRef]

44. Holscher, H.D.; Bauer, L.L.; Gourineni, V.; Pelkman, C.L.; Fahey, G.C., Jr.; Swanson, K.S. Agave Inulin Supplementation Affects the Fecal Microbiota of Healthy Adults Participating in a Randomized, Double-Blind, Placebo-Controlled, Crossover Trial. J. Nutr. 2015, 145, 2025-2032. [CrossRef] [PubMed]

45. Shen, R.L.; Dang, X.Y.; Dong, J.L.; Hu, X.Z. Effects of oat $\beta$-glucan and barley $\beta$-glucan on fecal characteristics, intestinal microflora, and intestinal bacterial metabolites in rats. J. Agric. Food Chem. 2012, 60, 11301-11308. [CrossRef]

46. Mao, G.; Li, S.; Orfila, C.; Shen, X.; Zhou, S.; Linhardt, R.J.; Ye, X.; Chen, S. Depolymerized RG-I-enriched pectin from citrus segment membranes modulates gut microbiota, increases SCFA production, and promotes the growth of Bifidobacterium spp., Lactobacillus spp. and Faecalibaculum spp. Food Funct. 2019, 10, 7828-7843. [CrossRef] [PubMed]

47. Beukema, M.; Akkerman, R.; Jermendi, E.; Koster, T.; Laskewitz, A.; Kong, C.; Schols, H.A.; Faas, M.M.; de Vos, P. Pectins that Structurally Differ in the Distribution of Methyl-Esters Attenuate Citrobacter rodentium-Induced Colitis. Mol. Nutr. Food Res. 2021, 65, 2100346. [CrossRef]

48. Calame, W.; Weseler, A.R.; Viebke, C.; Flynn, C.; Siemensma, A.D. Gum arabic establishes prebiotic functionality in healthy human volunteers in a dose-dependent manner. Br. J. Nutr. 2008, 100, 1269-1275. [CrossRef]

49. Rawi, M.H.; Abdullah, A.; Ismail, A.; Sarbini, S.R. Manipulation of Gut Microbiota Using Acacia Gum Polysaccharide. ACS Omega 2021, 6, 17782-17797. [CrossRef]

50. Kawakami, S.; Han, K.H.; Araki, T.; Ohba, K.; Wakabayashi, T.; Shimada, K.; Fukushima, M. Potato powders prepared by successive cooking-process depending on resistant starch content affect the intestinal fermentation in rats. Biosci. Biotechnol. Biochem. 2017, 81, 359-364. [CrossRef]

51. Li, T.; Teng, H.; An, F.; Huang, Q.; Chen, L.; Song, H. The beneficial effects of purple yam (Dioscorea alata L.) resistant starch on hyperlipidemia in high-fat-fed hamsters. Food Funct. 2019, 10, 2642-2650. [CrossRef] [PubMed]

52. Zeng, H.; Zheng, Y.; Lin, Y.; Huang, C.; Lin, S.; Zheng, B.; Zhang, Y. Effect of fractionated lotus seed resistant starch on proliferation of Bifidobacterium longum and Lactobacillus delbrueckii subsp. bulgaricus and its structural changes following fermentation. Food Chem. 2018, 268, 134-142. [CrossRef] [PubMed]

53. The Human Microbiome Project Consortium. Structure, function and diversity of the healthy human microbiome. Nature 2012, 486, 207-214. [CrossRef] [PubMed]

54. Sender, R.; Fuchs, S.; Milo, R. Revised Estimates for the Number of Human and Bacteria Cells in the Body. PLoS Biol. 2016, 14, e1002533. [CrossRef]

55. Almeida, A.; Nayfach, S.; Boland, M.; Strozzi, F.; Beracochea, M.; Shi, Z.J.; Pollard, K.S.; Sakharova, E.; Parks, D.H.; Hugenholtz, P.; et al. A unified catalog of 204,938 reference genomes from the human gut microbiome. Nat. Biotechnol. 2021, 39, 105-114. [CrossRef]

56. Costea, P.I.; Hildebrand, F.; Arumugam, M.; Backhed, F.; Blaser, M.J.; Bushman, F.D.; de Vos, W.M.; Ehrlich, S.D.; Fraser, C.M.; Hattori, M.; et al. Enterotypes in the landscape of gut microbial community composition. Nat. Microbiol. 2018, 3, 8-16. [CrossRef]

57. Singh, R.P. Glycan utilisation system in Bacteroides and Bifidobacteria and their roles in gut stability and health. Appl. Microbiol. Biotechnol. 2019, 103, 7287-7315. [CrossRef]

58. Flint, H.J.; Scott, K.P.; Duncan, S.H.; Louis, P.; Forano, E. Microbial degradation of complex carbohydrates in the gut. Gut Microbes 2012, 3, 289-306. [CrossRef]

59. Leitch, E.C.; Walker, A.W.; Duncan, S.H.; Holtrop, G.; Flint, H.J. Selective colonization of insoluble substrates by human faecal bacteria. Environ. Microbiol. 2007, 9, 667-679. [CrossRef]

60. Ze, X.; Duncan, S.H.; Louis, P.; Flint, H.J. Ruminococcus bromii is a keystone species for the degradation of resistant starch in the human colon. ISME J. 2012, 6, 1535-1543. [CrossRef]

61. El Kaoutari, A.; Armougom, F.; Gordon, J.I.; Raoult, D.; Henrissat, B. The abundance and variety of carbohydrate-active enzymes in the human gut microbiota. Nat. Rev. Microbiol. 2013, 11, 497-504. [CrossRef]

62. Foley, M.H.; Cockburn, D.W.; Koropatkin, N.M. The Sus operon: A model system for starch uptake by the human gut Bacteroidetes. Cell. Mol. Life Sci. 2016, 73, 2603-2617. [CrossRef]

63. Martens, E.C.; Lowe, E.C.; Chiang, H.; Pudlo, N.A.; Wu, M.; McNulty, N.P.; Abbott, D.W.; Henrissat, B.; Gilbert, H.J.; Bolam, D.N.; et al. Recognition and degradation of plant cell wall polysaccharides by two human gut symbionts. PLoS Biol. 2011, 9, e1001221. [CrossRef]

64. Shortt, C.; Hasselwander, O.; Meynier, A.; Nauta, A.; Fernandez, E.N.; Putz, P.; Rowland, I.; Swann, J.; Turk, J.; Vermeiren, J.; et al. Systematic review of the effects of the intestinal microbiota on selected nutrients and non-nutrients. Eur. J. Nutr. 2018, 57, 25-49. [CrossRef] 
65. Milani, C.; Lugli, G.A.; Duranti, S.; Turroni, F.; Bottacini, F.; Mangifesta, M.; Sanchez, B.; Viappiani, A.; Mancabelli, L.; Taminiau, B.; et al. Genomic encyclopedia of type strains of the genus Bifidobacterium. Appl. Environ. Microbiol. 2014, 80, 6290-6302. [CrossRef] [PubMed]

66. Koropatkin, N.M.; Cameron, E.A.; Martens, E.C. How glycan metabolism shapes the human gut microbiota. Nat. Rev. Microbiol. 2012, 10, 323-335. [CrossRef] [PubMed]

67. Holscher, H.D. Dietary fiber and prebiotics and the gastrointestinal microbiota. Gut Microbes 2017, 8, 172-184. [CrossRef]

68. Baxter, N.T.; Schmidt, A.W.; Venkataraman, A.; Kim, K.S.; Waldron, C.; Schmidt, T.M. Dynamics of Human Gut Microbiota and Short-Chain Fatty Acids in Response to Dietary Interventions with Three Fermentable Fibers. mBio 2019, 10, e02566-18. [CrossRef]

69. Tap, J.; Furet, J.P.; Bensaada, M.; Philippe, C.; Roth, H.; Rabot, S.; Lakhdari, O.; Lombard, V.; Henrissat, B.; Corthier, G.; et al. Gut microbiota richness promotes its stability upon increased dietary fibre intake in healthy adults. Environ. Microbiol. 2015, 17, 4954-4964. [CrossRef] [PubMed]

70. Shang, W.; Si, X.; Zhou, Z.; Li, Y.; Strappe, P.; Blanchard, C. Characterization of fecal fat composition and gut derived fecal microbiota in high-fat diet fed rats following intervention with chito-oligosaccharide and resistant starch complexes. Food Funct. 2017, 8, 4374-4383. [CrossRef]

71. Larsson, J.M.; Karlsson, H.; Sjovall, H.; Hansson, G.C. A complex, but uniform O-glycosylation of the human MUC2 mucin from colonic biopsies analyzed by nanoLC/MSn. Glycobiology 2009, 19, 756-766. [CrossRef]

72. Johansson, M.E.; Phillipson, M.; Petersson, J.; Velcich, A.; Holm, L.; Hansson, G.C. The inner of the two Muc2 mucin-dependent mucus layers in colon is devoid of bacteria. Proc. Natl. Acad. Sci. USA 2008, 105, 15064-15069. [CrossRef]

73. Wrzosek, L.; Miquel, S.; Noordine, M.L.; Bouet, S.; Chevalier-Curt, M.J.; Robert, V.; Philippe, C.; Bridonneau, C.; Cherbuy, C.; Robbe-Masselot, C.; et al. Bacteroides thetaiotaomicron and Faecalibacterium prausnitzii influence the production of mucus glycans and the development of goblet cells in the colonic epithelium of a gnotobiotic model rodent. BMC Biol. 2013, 11, 61. [CrossRef]

74. Windey, K.; De Preter, V.; Verbeke, K. Relevance of protein fermentation to gut health. Mol. Nutr. Food Res. 2012, 56, 184-196. [CrossRef] [PubMed]

75. Schroeder, B.O.; Birchenough, G.M.H.; Stahlman, M.; Arike, L.; Johansson, M.E.V.; Hansson, G.C.; Backhed, F. Bifidobacteria or Fiber Protects against Diet-Induced Microbiota-Mediated Colonic Mucus Deterioration. Cell Host Microbe 2018, 23, $27-40 . e 7$. [CrossRef]

76. Makki, K.; Deehan, E.C.; Walter, J.; Backhed, F. The Impact of Dietary Fiber on Gut Microbiota in Host Health and Disease. Cell Host Microbe 2018, 23, 705-715. [CrossRef] [PubMed]

77. Zou, J.; Chassaing, B.; Singh, V.; Pellizzon, M.; Ricci, M.; Fythe, M.D.; Kumar, M.V.; Gewirtz, A.T. Fiber-Mediated Nourishment of Gut Microbiota Protects against Diet-Induced Obesity by Restoring IL-22-Mediated Colonic Health. Cell Host Microbe 2018, 23, 41-53.e4. [CrossRef]

78. Burton-Freeman, B. Dietary fiber and energy regulation. J. Nutr. 2000, 130, 272S-275S. [CrossRef]

79. Howarth, N.C.; Saltzman, E.; Roberts, S.B. Dietary fiber and weight regulation. Nutr. Rev. 2001, 59, 129-139. [CrossRef]

80. Ratanpaul, V.; Williams, B.A.; Black, J.L.; Gidley, M.J. Review: Effects of fibre, grain starch digestion rate and the ileal brake on voluntary feed intake in pigs. Animal 2019, 13, 2745-2754. [CrossRef]

81. Benton, D.; Young, H.A. Reducing Calorie Intake May Not Help You Lose Body Weight. Perspect. Psychol. Sci. 2017, 12, 703-714. [CrossRef]

82. Jia, W.; Xie, G.; Jia, W. Bile acid-microbiota crosstalk in gastrointestinal inflammation and carcinogenesis. Nat. Rev. Gastroenterol. Hepatol. 2018, 15, 111-128. [CrossRef] [PubMed]

83. Ridlon, J.M.; Kang, D.J.; Hylemon, P.B. Bile salt biotransformations by human intestinal bacteria. J. Lipid Res. 2006, 47, 241-259. [CrossRef]

84. Chiang, J.Y. Bile acids: Regulation of synthesis. J. Lipid Res. 2009, 50, 1955-1966. [CrossRef] [PubMed]

85. Chiang, J.Y.L.; Ferrell, J.M. Bile Acids as Metabolic Regulators and Nutrient Sensors. Annu. Rev. Nutr. 2019, 39, 175-200. [CrossRef]

86. Baye, K.; Guyot, J.P.; Mouquet-Rivier, C. The unresolved role of dietary fibers on mineral absorption. Crit. Rev. Food Sci. Nutr. 2017, 57, 949-957. [CrossRef]

87. Bosscher, D.; Van Caillie-Bertrand, M.; Deelstra, H. Effect of thickening agents, based on soluble dietary fiber, on the availability of calcium, iron, and zinc from infant formulas. Nutrition 2001, 17, 614-618. [CrossRef]

88. Fung, K.Y.; Cosgrove, L.; Lockett, T.; Head, R.; Topping, D.L. A review of the potential mechanisms for the lowering of colorectal oncogenesis by butyrate. Br. J. Nutr. 2012, 108, 820-831. [CrossRef]

89. Chang, P.V.; Hao, L.; Offermanns, S.; Medzhitov, R. The microbial metabolite butyrate regulates intestinal macrophage function via histone deacetylase inhibition. Proc. Natl. Acad. Sci. USA 2014, 111, 2247-2252. [CrossRef]

90. Singh, N.; Thangaraju, M.; Prasad, P.D.; Martin, P.M.; Lambert, N.A.; Boettger, T.; Offermanns, S.; Ganapathy, V. Blockade of dendritic cell development by bacterial fermentation products butyrate and propionate through a transporter (Slc5a8)-dependent inhibition of histone deacetylases. J. Biol. Chem. 2010, 285, 27601-27608. [CrossRef]

91. Furusawa, Y.; Obata, Y.; Fukuda, S.; Endo, T.A.; Nakato, G.; Takahashi, D.; Nakanishi, Y.; Uetake, C.; Kato, K.; Kato, T.; et al. Commensal microbe-derived butyrate induces the differentiation of colonic regulatory T cells. Nature 2013, 504, 446-450. [CrossRef] 
92. Arpaia, N.; Campbell, C.; Fan, X.; Dikiy, S.; van der Veeken, J.; deRoos, P.; Liu, H.; Cross, J.R.; Pfeffer, K.; Coffer, P.J.; et al. Metabolites produced by commensal bacteria promote peripheral regulatory T-cell generation. Nature 2013, 504, 451-455. [CrossRef]

93. Nepelska, M.; Cultrone, A.; Beguet-Crespel, F.; Le Roux, K.; Dore, J.; Arulampalam, V.; Blottiere, H.M. Butyrate produced by commensal bacteria potentiates phorbol esters induced AP-1 response in human intestinal epithelial cells. PLoS ONE 2012, 7, e52869. [CrossRef] [PubMed]

94. Brown, A.J.; Goldsworthy, S.M.; Barnes, A.A.; Eilert, M.M.; Tcheang, L.; Daniels, D.; Muir, A.I.; Wigglesworth, M.J.; Kinghorn, I.; Fraser, N.J.; et al. The Orphan G protein-coupled receptors GPR41 and GPR43 are activated by propionate and other short chain carboxylic acids. J. Biol. Chem. 2003, 278, 11312-11319. [CrossRef] [PubMed]

95. Singh, N.; Gurav, A.; Sivaprakasam, S.; Brady, E.; Padia, R.; Shi, H.; Thangaraju, M.; Prasad, P.D.; Manicassamy, S.; Munn, D.H.; et al. Activation of Gpr109a, receptor for niacin and the commensal metabolite butyrate, suppresses colonic inflammation and carcinogenesis. Immunity 2014, 40, 128-139. [CrossRef]

96. Macia, L.; Tan, J.; Vieira, A.T.; Leach, K.; Stanley, D.; Luong, S.; Maruya, M.; McKenzie, C.I.; Hijikata, A.; Wong, C.; et al. Metabolite-sensing receptors GPR43 and GPR109A facilitate dietary fibre-induced gut homeostasis through regulation of the inflammasome. Nat. Commun. 2015, 6, 6734. [CrossRef]

97. Kimura, I.; Ozawa, K.; Inoue, D.; Imamura, T.; Kimura, K.; Maeda, T.; Terasawa, K.; Kashihara, D.; Hirano, K.; Tani, T.; et al. The gut microbiota suppresses insulin-mediated fat accumulation via the short-chain fatty acid receptor GPR43. Nat. Commun. 2013, 4, 1829. [CrossRef] [PubMed]

98. Samuel, B.S.; Shaito, A.; Motoike, T.; Rey, F.E.; Backhed, F.; Manchester, J.K.; Hammer, R.E.; Williams, S.C.; Crowley, J.; Yanagisawa, M.; et al. Effects of the gut microbiota on host adiposity are modulated by the short-chain fatty-acid binding $\mathrm{G}$ protein-coupled receptor, Gpr41. Proc. Natl. Acad. Sci. USA 2008, 105, 16767-16772. [CrossRef]

99. Eswaran, S.; Muir, J.; Chey, W.D. Fiber and functional gastrointestinal disorders. Am. J. Gastroenterol. 2013, 108, 718-727. [CrossRef]

100. El-Salhy, M.; Gundersen, D. Diet in irritable bowel syndrome. Nutr. J. 2015, 14, 36. [CrossRef]

101. Riedl, J.; Linseisen, J.; Hoffmann, J.; Wolfram, G. Some dietary fibers reduce the absorption of carotenoids in women. J. Nutr. 1999, 129, 2170-2176. [CrossRef] [PubMed]

102. Ten Bruggencate, S.J.; Bovee-Oudenhoven, I.M.; Lettink-Wissink, M.L.; Van der Meer, R. Dietary fructooligosaccharides increase intestinal permeability in rats. J. Nutr. 2005, 135, 837-842. [CrossRef]

103. Singh, V.; Yeoh, B.S.; Chassaing, B.; Xiao, X.; Saha, P.; Olvera, R.A.; Lapek, J.D., Jr.; Zhang, L.; Wang, W.B.; Hao, S.; et al. Dysregulated Microbial Fermentation of Soluble Fiber Induces Cholestatic Liver Cancer. Cell 2018, 175, 679-694.e22. [CrossRef] [PubMed]

104. Bernstein, H.; Bernstein, C.; Payne, C.M.; Dvorak, K. Bile acids as endogenous etiologic agents in gastrointestinal cancer. World J. Gastroenterol. 2009, 15, 3329-3340. [CrossRef]

105. Zhang, C.; Zhang, M.; Wang, S.; Han, R.; Cao, Y.; Hua, W.; Mao, Y.; Zhang, X.; Pang, X.; Wei, C.; et al. Interactions between gut microbiota, host genetics and diet relevant to development of metabolic syndromes in mice. ISME J. 2010, 4, 232-241. [CrossRef]

106. Mozaffarian, D.; Hao, T.; Rimm, E.B.; Willett, W.C.; Hu, F.B. Changes in diet and lifestyle and long-term weight gain in women and men. N. Engl. J. Med. 2011, 364, 2392-2404. [CrossRef] [PubMed]

107. Wang, T.; Cai, G.; Qiu, Y.; Fei, N.; Zhang, M.; Pang, X.; Jia, W.; Cai, S.; Zhao, L. Structural segregation of gut microbiota between colorectal cancer patients and healthy volunteers. ISME J. 2012, 6, 320-329. [CrossRef]

108. O'Keefe, S.J.; Li, J.V.; Lahti, L.; Ou, J.; Carbonero, F.; Mohammed, K.; Posma, J.M.; Kinross, J.; Wahl, E.; Ruder, E.; et al. Fat, fibre and cancer risk in African Americans and rural Africans. Nat. Commun. 2015, 6, 6342. [CrossRef]

109. Nilsson, A.C.; Johansson-Boll, E.V.; Bjorck, I.M. Increased gut hormones and insulin sensitivity index following a 3-d intervention with a barley kernel-based product: A randomised cross-over study in healthy middle-aged subjects. Br. J. Nutr. 2015, 114, 899-907. [CrossRef]

110. Nicolucci, A.C.; Hume, M.P.; Martinez, I.; Mayengbam, S.; Walter, J.; Reimer, R.A. Prebiotics Reduce Body Fat and Alter Intestinal Microbiota in Children Who Are Overweight or With Obesity. Gastroenterology 2017, 153, 711-722. [CrossRef]

111. Davison, K.M.; Temple, N.J. Cereal fiber, fruit fiber, and type 2 diabetes: Explaining the paradox. J. Diabetes Its Complicat. 2018, 32, 240-245. [CrossRef] [PubMed] 